\title{
Advances in D. melanoxylon Investigations towards Tissue Culture: Problems and Limitations
}

\author{
Washa B. Washa1, A. M. S. Nyomora² \\ ${ }^{1}$ Mkwawa University College of Education (MUCE), Iringa, Tanzania \\ ${ }^{2}$ Botany Department, University of Dar es salaam, Dar es salaam, Tanzania \\ Email: wbugalama@yahoo.com, anyomora@gmail.com
}

Received 20 September 2014; revised 19 October 2014; accepted 5 November 2014

Academic Editor: Ibrahim A. Ibrahim, Genetic Engineering and Biotechnology Research Institute (GEBRI), University of Sadat City, Egypt

Copyright (C) 2014 by authors and Scientific Research Publishing Inc.

This work is licensed under the Creative Commons Attribution International License (CC BY). http://creativecommons.org/licenses/by/4.0/

(c) (i) Open Access

\section{Abstract}

The first attempt on D. melanoxylon tissue culture was conducted from 2010 to 2013 at a high level of expectations. A total of $\mathbf{5 0 0}$ seeds were sterilized at different concentration of reagents and inoculated at different strength of the Murashige and Skoog medium for germination to obtain disease free explants for callus induction trials. A total of 400 nodal segments obtained from germinated seeds were sterilized at different concentration of reagents and inoculated at different hormonal combinations to induce callus formation for seedling multiplication. Results from this tissue culture attempt set a foundation for tissue culture success in D. melanoxylon on the future research. Only $19.8 \%$ of seeds inoculated in half strength of Murashige and Skoog medium germinated within 7 days while only $6.8 \%$ of seeds inoculated in full strength of Murashige and Skoog medium germinated within 6 days. This germination was at sterilization of 20 minutes in $35 \%$ ethanol and 20 minutes in $2.6 \%$ sodium hypochlorite. A total of $1 \%$ of inoculated $D$. melanoxylon seedling fragments in Murashige and Skoog media supplemented with hormone combination at $2.0 \mathrm{mg} / 1 \mathrm{BAP}+0.5 \mathrm{mg} / \mathrm{l}$ NAA developed callus after16 days from the inoculation day. The final weight of the callus at the last record was $0.62 \mathrm{~g}$. In this induction ex-plants were surface sterilized in $35 \%$ ethanol for 20 minutes and $2.6 \%$ sodium hypochlorite solution for 20 minutes. The color of callus was green and friable in nature. Other hormonal combinations in this case did not induce callus production. These results suggested that the problems which affect seed germination in the natural environment are also reflected on germination in the Murashige and Skoog medium and in callus induction. Vulnerability to fungal attack is a limitation for successful callus induction and germination in the culture room. More research under improved sterile conditions is needed to improve callus percentage for seedling multiplication. 


\section{Keywords}

\section{Dalbergia melanoxylon, Tissue Culture, Callus Induction, Explants, Murashige and Skoog}

\section{Introduction}

Initially was reported that seed harvested between 8 - 12 weeks from their maturity germinated to $35 \%$ and viability was $57 \%$ while the seeds harvested 16 weeks and above germinated to $21 \%$ and viability was $37 \%$. The problem and limitation is that $D$. melanoxylon seeds lose their viability few weeks from their maturity on the tree [1].

In the follow-up findings was reported that juvenile stem cuttings rooted to $72 \%$ by IBA treatment compared to $20 \%$ rooting of the older stem cuttings. The reported limitation for using the method for propagation of the species is that it involves huge harvesting of roots from the existing plants which is considered to be deforestation [2].

Different plant species are reported to respond differently to different tissue culture media in different sterilization conditions as these plants differ anatomically and physically [3].

Socio-economic importance including local and commercial use of the Dalbergia melanoxylon wood to individuals as well as international with at the mid of 1900's was a reason for researchers to start investigations on the species especially on the ethnobotany and silviculture of the species [4] and [5].

Little knowledge obtained for ethnobotany and silviculture of the species in this period increased awareness of traders to work on the Blackwood and expensive timber of D. melanoxylon leading to the rapid depression of the abundance of the D. melanoxylon in the late 1900's [6]. One of the problems noted from the mid to the late 1900 's was the slow rotation time of the species to the harvestable age and difficult of the seed to germinate under natural conditions. The rotation time was reported to be 70 to 100 years and seed germination under natural conditions was reported to be below 50\%. These periods were limited by lack of tissue culture technology for multiple productions of the species in the controlled environments. As a result of this limitation the gap between harvesting and natural regeneration of the species became a threat to the future existence of the species and to date the species is classified in the Lower/Risk near threatened in Tanzania, threatened in Kenya and extinct in Burkina Faso as reported in the Red list category [6].

In recent years efforts to improve propagation of $D$. melanoxylon started and were directed on how to improve seed germination, rooting of the cuttings, rotation time (growth rate), seedling multiplication and investigations on factors affecting seed germination in the natural environments ([7]-[15]).

It was reported that $56 \%$ of the species seedlings in the forest originate from root suckers. The problem of using this method for propagation of the species is a destructive practice of the existing plants and the limitation is that seedlings from root suckers do not develop a tap root which is important for growth of the plant [16].

It was reported that available moisture content is the main factor affecting seed germination in the natural environment. Seeds are vulnerable to high moisture level and vulnerable to fungal and insect attack. As a result of this vulnerability, seeds tends lose their viability rapidly as they mature from their mother plants [17].

Again was reported two ectomycorrhiza species and one endomycorrhiza species to be associated with $D$. melanoxylon but also the association influenced $100 \%$ rooting of the softwood stem cuttings of the species in the non-mist propagator [18].

Finally were reported two findings in two different investigations. The first investigation reported seeds to germinate to $21 \%$ in the soil compared to $19.8 \%$ for seed germinated in the Murashige and Skoog (MS) medium in the culture room. Germination in the MS was hindered by fungal contamination of seeds in the medium as a limitation. The problem here is that $D$. melanoxylon is still not domesticated and therefore have a lot of born in fungal disease. The second investigation reported root cuttings to root to $37 \%$ and softwood cuttings of less than 15 gm by weight rooted to $100 \%$ in the non-mist propagator [19] and [20]).

Reported findings from ethnobotany to rooting trials did not give a sustainable propagation methods of $D$. melanoxylon because germination is still limited by low seed viability in the natural environment, root suckers seedlings are limited by lack of tap roots, rooting of the stem cuttings are limited by deforestation of the existing plants by root harvesting. Tissue culture in $D$. melanoxylon therefore was conducted as an alternative to sustainable means of propagating the species. The main concern of this paper therefore is to report the first attempt 
in D. melanoxylon tissue culture, findings, Problems and limitations in conducting D. melanoxylon tissue culture.

\subsection{Material and Methods}

A total of $2 \mathrm{~kg}$ of Dalbergia melanoxylon seeds from Bwawani collection was purchased from TTSA in September 2010. Other 4 pots bearing 4 days old D. melanoxylon seedlings from Dakawa seed collection were purchased from TTSA on March 2012 and taken to the tissue culture laboratory at the Botany Department University of Dar es Salaam. Seeds were used for raising disease-free shoots in Murashige and Skoog media for callus induction trials while the purchased young seedlings were used for callus induction trials. Preparation and administration of tissue culture and culture materials were conducted according to recommended standards.

\subsection{Dalbergia melanoxylon Seed Sterilization and Inoculation}

A total of 500 seeds were used in this experiment in 10 replicates having 50 seeds in 5 Petri dish per replicate. The purpose was to compare full and half strength MS in effecting seed germination. This experiment was conducted hand to hand with callus induction trial phase I during October 2010-October 2011 because obtained seedlings were used for callus induction trial. About one hundred and fifty (150) seeds were sterilized using $70 \%$ ethanol for 30 minutes and 2.6\% sodium hypochlorite for 30 minutes and inoculated in full strength MS at pH 5.8 in 15 Petri dish (3 replicates). Another 100 seeds were sterilized in 35\% ethanol for 20 minutes and 2.6\% sodium hypochlorite for 20 minutes and inoculated in half strength MS at $5.8 \mathrm{pH}$ in 10 Petri-dish (2 replicates). Other 150 seeds were sterilized in $70 \%$ ethanol for 10 minutes and $2.6 \%$ sodium hypochlorite for 10 minutes and inoculated in full strength MS at pH 5.8 in 15 petri dish (3 replicates) while the last 100 seeds were sterilized in $35 \%$ ethanol for 10 minutes and $2.6 \%$ sodium hypochlorite for 10 minutes and inoculated in half strength MS at $5.8 \mathrm{pH}$ in 10 Petri dish (2 replicates). The cultures were incubated in a culture room at $28^{\circ} \mathrm{C}$ under a photoperiod of 16 hours at 3000 lux light intensity provided by cool white fluorescent tubes.

\subsection{Callus Induction Trials from Seed Germinated Seedlings (Phase I)}

A total of 20 nodal explants of Dalbergia melanoxylon per replicate were used as experimental material in phase I. Ten (10) replicates with 20 Petri-dishes each replicate and one node segment in each petri-dish was conducted. All shoots were collected from 2 to 4 days old germinated seeds. These shoot ex-plants were surface sterilized with 35\% ethanol for 20 minutes and rinsed with sterilized water three times. Explants were then treated with 2.6\% sodium hypochlorite solution for 20 minutes and rinsed with sterilized water three times for inoculation in full strength MS medium at pH 5.8 in 10 replicates during October 2010-October 2011. The MS media used in all callus induction trials were industrial to avoid measurement errors and to save time.

Three replicates used 10 minutes, four replicates used 20 minutes and other three replicates used 30 minutes to sterilize explants in $35 \%$ ethanol and $2.6 \%$ sodium hypochlorite solution. The cultures were incubated in a culture room at $28^{\circ} \mathrm{C}$ under a photoperiod of 16 hours at 3000 lux light intensity provided by cool white fluorescent tubes. Different ratios of hormones (BAP + NAA, BAP + IAA, BAP + IBA, KIN + NAA) were used to initiate callus. Definitions for hormones abbreviated are given as: BAP is benzyl amino purine, NAA is 1-naphthaleneacetic acid, IAA is indole-3-acetic acid, IBA is indolebutyric acid and KIN is kinetin.

\subsection{Callus Induction Trials from Seed Germinated Seedlings (Phase II)}

In the callus induction trial phase II conducted between 17 March 2012 and 30 April 2012 using seedlings bought from TTSA (plate 8), only BAP + NAA hormone combination was used since it was the only combination that had induced at least $0.5 \%$ callus in phase I. Under this phase a total of 20 nodal explants of Dalbergia melanoxylon per replicate were used as experimental material. Ten (10) replicates with 20 Petri-dishes each replicate and one node segment in each petri-dish was conducted. All shoots were collected from 2 to 4 days old seedlings. These shoot ex-plants were surface sterilized with 35\% ethanol for 20 minutes and rinsed with sterilized water three times. Explants were then treated with 2.6\% sodium hypochlorite solution for 20 minutes and rinsed with sterilized water three times for inoculation in full strength MS medium at $\mathrm{pH} 5.8$. Three replicates used 10 minutes, four replicates used 20 minutes and other three replicates used 30 minutes to sterilize explants in $35 \%$ ethanol and $2.6 \%$ sodium hypochlorite solution. The cultures were incubated in a culture room at $28^{\circ} \mathrm{C}$ under a photoperiod of 16 hours at 3000 lux light intensity provided by cool white fluorescent tubes. 


\section{Results}

\subsection{D. melanoxylon Seed Germination in MS Media}

A total of $19.8 \%$ of seeds inoculated in half strength of MS medium germinated within 7 days after sterilization of 20 minutes in $35 \%$ ethanol and 20 minutes in $2.6 \%$ sodium hypochlorite while only $6.8 \%$ of seeds inoculated in full strength of MS medium germinated within 6 days after sterilization of 30 minutes in 70\% ethanol and 30 minutes in 2.6\% sodium hypochlorite (Plate 1, Table 1 and Figure 1).

\subsection{Results of Callus Induction Trials in Phase I and II}

Among the four types of hormonal combinations and their concentrations on 200 shoot segments of Dalbergia melanoxylon, callus induction in phase I was observed only in 1 inoculated shoot segment with hormone combination comprising of BAP and NAA. It was observed that only $0.5 \%$ of inoculated $D$. melanoxylon seedling fragments in MS media supplemented with hormone combination at $2.0 \mathrm{mg} / \mathrm{l} \mathrm{BAP}+0.5 \mathrm{mg} / \mathrm{l} \mathrm{NAA}$ developed callus after16 days from the inoculation day. The final weight of the callus at the last record was $0.62 \mathrm{~g}$. In this induction ex-plants were surface sterilized in 35\% ethanol for 20 minutes and $2.6 \%$ sodium hypochlorite solution for 20 minutes. The color of callus was green and friable in nature. Other hormonal combinations in this case did not induce callus production (Plate 2, Table 2, Table 3 and Figure 2).

In the callus induction trial phase II also 1 nodal segment among 200 nodes developed callus using hormone combination at $2.0 \mathrm{mg} / \mathrm{l} \mathrm{BAP}+0.5 \mathrm{mg} / \mathrm{l} \mathrm{NAA}$ in 16 days from the inoculation day. This was also $0.5 \%$ callus of the inoculated ex-plants making a total of $1 \%$ callus from the total of 400 nodes inoculated in phase I and phase II. In this induction ex-plants were surface sterilized in 35\% ethanol for 20 minutes and $2.6 \%$ sodium hypochlorite solution for 20 minutes. Growth of callus in phase II was observed increasing in size from day four to day eight (Plate 3, Table 4 and Figure 3). The weight of callus at the last record was $0.62 \mathrm{~g}$. The color of callus was green and friable in nature

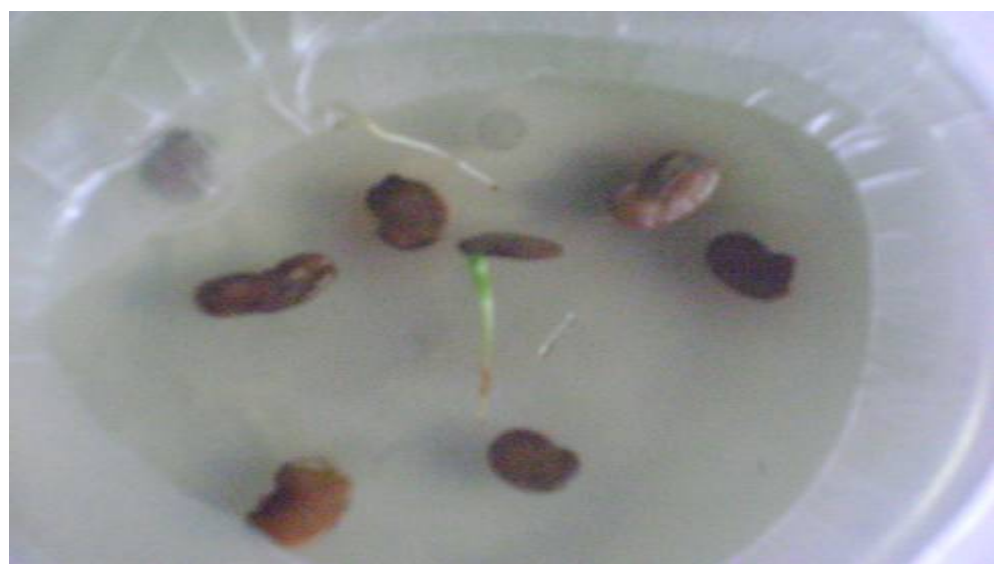

Plate 1. Representative for germinated seeds in MS media.

Germ. \%

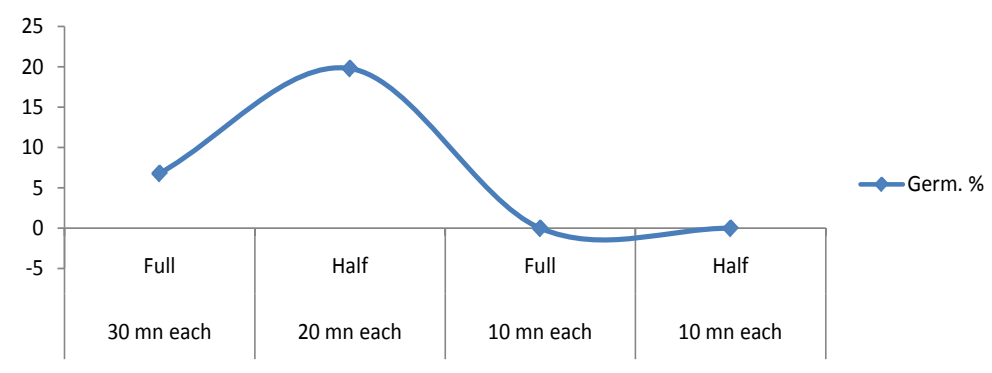

Figure 1. Effect of sterilization reagent and duration on seed germination. 
Table 1. Summary for sterilization conditions and germination percentage in the MS.

\begin{tabular}{|c|c|c|c|c|}
\hline \#seeds & Sterilization type & Sterilization duration & MS strength & Germination \% \\
\hline 150 & $70 \%$ ethanol \& $2.6 \%$ sodium hypochlorite & 30 minutes each & Full strength & 6.8 \\
\hline 100 & $35 \%$ ethanol \& $2.6 \%$ sodium hypochlorite & 20 minutes each & Half strength & 19.8 \\
\hline 150 & $70 \%$ ethanol \& $2.6 \%$ sodium hypochlorite & 10 minutes each & Full strength & 0,0 \\
\hline 100 & $35 \%$ ethanol \& $2.6 \%$ sodium hypochlorite & 10 minutes each & Half strength & 0.0 \\
\hline
\end{tabular}

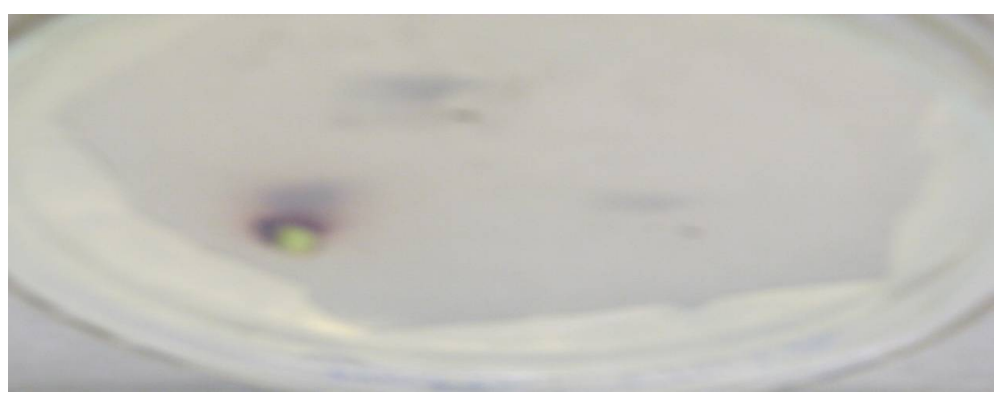

Plate 2. Two days old callus (Phase I).

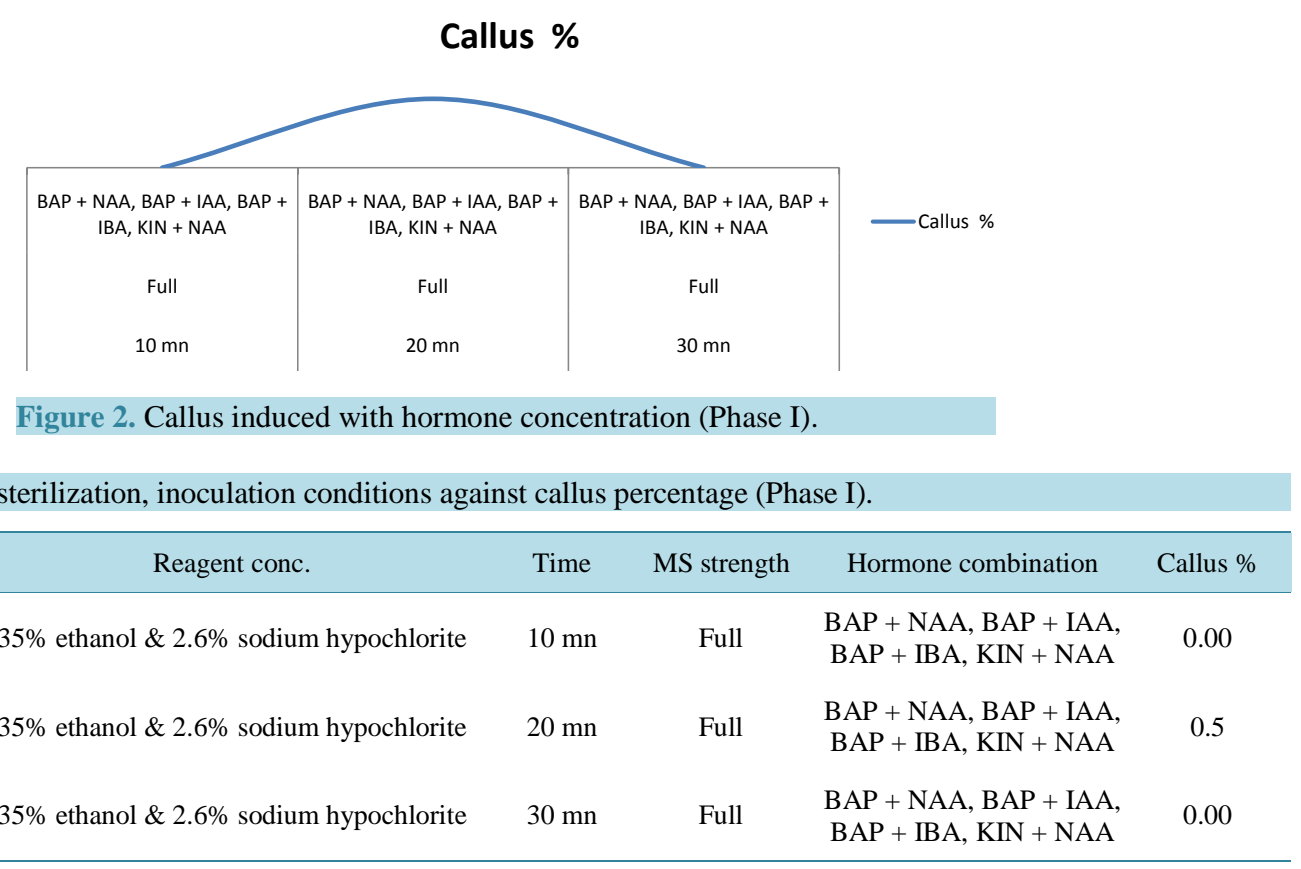

\section{Discussion, Conclusion and Recommendation}

\subsection{Callus Induction in Dalbergia melanoxylon}

Seeds, nodes, shoot and root tips are efficient ex-plant source for many plant callus initiation and shoot regeneration. This idea was adopted in this study expecting that $D$. melanoxylon ex-plants can easily develop callus by tissue culture. Protocols for tissue culture differ from one plant species to another. Some plant species can respond to many media combinations, others can respond to only one media combination while others do not respond to any media combination. Different cellular and morphological structures in different plants have lead to different preparation and sterilization protocols in different plants species.

Most domesticated plant species have been subjected to genetic transformation such as chromosomal and DNA recombination in such a way that they can be easily accessed and sterilized for tissue culture. D. melanox 


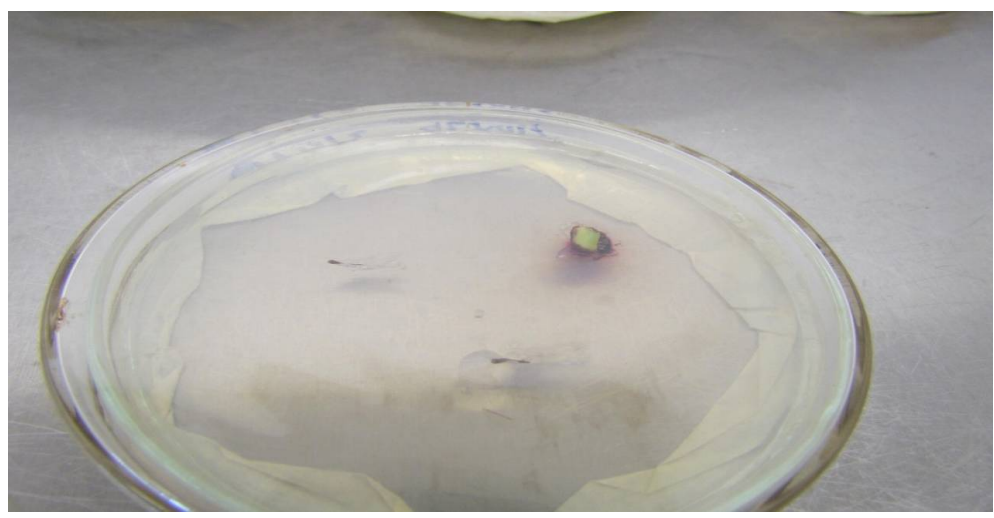

Plate 3. Four days old callus (Phase II).

\section{Callus \%}

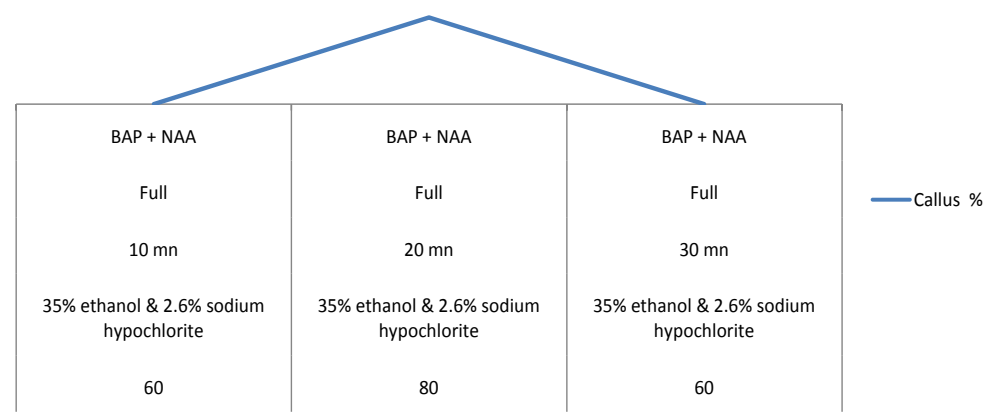

Figure 3. Callus induced with hormone concentration (Phase II).

Table 3. Effect of different concentration of hprmones in MS medium for induction of callus from the shoot tip segments of Dalbergia melanoxylon Phase I (NB: Gn.F means Green and friable).

\begin{tabular}{|c|c|c|c|c|}
\hline Growth regulator & $\begin{array}{l}\text { Concentration } \\
\text { (mg/l)/petri-dish }\end{array}$ & $\begin{array}{c}\text { Days to callus } \\
\text { Formation }\end{array}$ & $\begin{array}{c}\% \text { of explants } \\
\text { responded }\end{array}$ & $\begin{array}{l}\text { Type of } \\
\text { callus }\end{array}$ \\
\hline \multirow{5}{*}{$\mathrm{BAP}+\mathrm{NAA}$} & $1.5+0.5$ & -- & -- & -- \\
\hline & $1.5+1.0$ & -- & -- & -- \\
\hline & $2.0+0.1$ & -- & -- & -- \\
\hline & $2.0+0.5$ & 16 & 0.5 & Gn.F \\
\hline & $2.0+1.0$ & -- & -- & -- \\
\hline \multirow{5}{*}{$\mathrm{BAP}+\mathrm{IBA}$} & $1.5+0.5$ & -- & -- & -- \\
\hline & $1.5+1.0$ & -- & -- & -- \\
\hline & $2.0+0.1$ & -- & -- & -- \\
\hline & $2.0+0.5$ & -- & -- & -- \\
\hline & $2.0+1.0$ & -- & -- & -- \\
\hline \multirow{5}{*}{$\mathrm{BAP}+\mathrm{IAA}$} & $1.5+0.5$ & -- & -- & -- \\
\hline & $1.5+1.0$ & -- & -- & -- \\
\hline & $2.0+0.1$ & -- & -- & -- \\
\hline & $2.0+0.5$ & -- & -- & -- \\
\hline & $2.0+1.0$ & -- & -- & -- \\
\hline \multirow{5}{*}{$\mathrm{KIN}+\mathrm{NAA}$} & $1.5+0.5$ & -- & -- & -- \\
\hline & $1.5+1.0$ & -- & -- & -- \\
\hline & $2.0+0.1$ & -- & -- & -- \\
\hline & $2.0+0.5$ & -- & -- & -- \\
\hline & $2.0+1.0$ & -- & -- & -- \\
\hline
\end{tabular}


Table 4. Summary of sterilization, inoculation conditions against callus percentage (Phase II).

\begin{tabular}{cccccc}
\hline \#shoot segments & Reagent conc. & Time & MS strength & Hormone combination & Callus \% \\
\hline 60 & $35 \%$ ethanol \& 2.6\% sodium hypochlorite & $10 \mathrm{mn}$ & Full & BAP + NAA & 0.00 \\
80 & $35 \%$ ethanol \& 2.6\% sodium hypochlorite & $20 \mathrm{mn}$ & Full & BAP + NAA & 0.5 \\
60 & $35 \%$ ethanol \& 2.6\% sodium hypochlorite & $30 \mathrm{mn}$ & Full & BAP + NAA & 0.00 \\
\hline
\end{tabular}

ylon is one of the forest plant which is neither genetically transformed nor domesticated and therefore is colonized by various microorganisms hence is difficult to keep in aseptic conditions for tissue culture. For such forest plants it needs so many trials of sterilizing materials such as ethanol and sodium hypochlorite. Some treatment combinations of $D$. melanoxylon ex-plants in this study did not generate callus or seed germination in the media because there were either no viable seeds, sterilization was not enough or sterilization killed the seed embryos since the extent of sterilizing and ratios for ethanol and sodium hypochlorite and the hormonal combination ratios for D. melanoxylon was not known. For plant which is subjected to tissue culture for the first time such as $D$. melanoxylon, the conditions and parameters needs many trials to be known including hours of light exposure of inoculated materials, hours in darkness, quantity and quality of light intensity, temperature and type of ex-plant which can respond easily. All these have lead to difficulties for D. melanoxylon callus induction in this study.

\subsection{Sterilization of D. melanoxylon Ex-Plants}

Two different sterilization ratios were interchangeably used for $D$. melanoxylon seeds and node tips and they gave different inoculum results. When sterilized in $35 \%$ ethanol for 30 minutes and $2.6 \%$ sodium hypochlorite for 30 minutes, most of cultures remained uncontaminated but did not produce callus.

Three interpretation can be given to these results: one is successful sterilization but which killed the ex-plants, second is successful sterilization but there was no viable ex-plant in the trial, lastly is that some other necessary conditions are not attained such as light intensity or temperature. Other sterilization trials were subjected to $70 \%$ ethanol for 30 minutes and 2.6\% sodium hypochlorite for 30 minutes. In this trial inoculums also did not get contaminated but also did not produce callus or germinate the seed meaning that sterilization was successful but killed the ex-plants or sterilization was successful but there was no viable ex-plant in the trial or any other necessary condition was not attained. When only10 minutes was used to sterilize D. melanoxylon, ex-plants in either $35 \%$ ethanol and $2.6 \%$ hypochlorite or $70 \%$ ethanol and $2.6 \%$ sodium hypochlorite all inoculums became contaminated meaning that this duration does not keep the ex-plants in aseptic conditions. Full strength MS is more recommended for callus induction in woody plants which are difficult to give callus. However, $70 \%$ ethanol sterilization is not recommended for shoot segments since they have delicate young dividing cells.

When 20 minutes was used to sterilize D. melanoxylon ex-plants in either $35 \%$ ethanol or $70 \%$ ethanol at least $19.8 \%$ of inoculated ex-plants germinated and a total of $1 \%$ ex-plants developed callus meaning that this duration did not kill cells or embryo of all ex-plants but also sterilized successful most of the viable ex-plants. This range of concentrations and duration for sterilizing D. melanoxylon ex-plants is in agreement with [5] who reported that "some plant species can respond to many media combinations, others can respond to only one media combination while others do not respond to any media combination".

A protocol was obtained from this research for inducing callus from $D$. melanoxylon shoots. The callus producing protocol was from a 4 days old $D$. melanoxylon seedlings. Seedlings which were below 4 days old were too fragile and easily dried out when inoculated, where as seedlings above 28 days old did not develop callus. Hormone combination comprising of benzyl amino purine (BAP) and naphthalene acetic Acid (NAA) induced at least $1 \%$ callus formation. When full strength MS media was used, callus formation was induced as opposed to half strength MS media. Sterilization of 35\% ethanol for 20 minutes and 2.6\% sodium hypochlorite solution for 20 minutes of shoot segments produced sterile environment for callus formation. Other sterilization concentrations could not induce callus formation in this particular study. Such a new species in tissue culture needs as many trials as possible to conclude appropriate ratios for vitamins, hormones, type and $\mathrm{pH}$ level as well as duration of sterilization of ex-plants. D. melanoxylon to date is not a domesticated plant as most of the successful plants in tissue culture such as tomato and banana. Most of the wild woody plant species are difficult to regene- 
rate using tissue culture.

Ninety percent $(90 \%)$ of $D$. melanoxylon seeds inoculated for germination trial in the laminar flow were attacked by fungus before germinating. This was probably due to the fact that the seeds of the species have seed borne fungal infections but this should be investigated further to justify. The fungus attacks were also observed on seeds inoculated in soil media. Tissue culture experiments require unlimited time. Success of micropropagation in cassava by DNA recombination, sisal by meristematic tissue culture, cashew nuts by callus tissue culture and banana by suckers micropropagation came after genetic transformation and to some of them domestication and hence became easily assessed in tissue culture. If researchers could have genetically transformed $D$. melanoxylon today, getting a callus induction and other protocols of the species could not be so difficult since a species could be easily assessed in tissue culture. So genetic transformation was ideal for $D$. melanoxylon before getting into mass production of planting materials of the species but this is a good start to the world of science.

\subsection{Problems and Limitations in Conducting D. melanoxylon Tissue Culture}

Being a forest plant as a problem, $D$. melanoxylon is easily attacked by fungal disease in the process to germination and callus induction in the culture room. This was the most limitation of the experiment to obtain recommended germination percentage and callus percentage. To improve callus induction needs techniques to overcome fungal contaminations in the culture room.

\section{References}

[1] Amri, E (2008) Effect of Timing of Seed Collections an Provenances on Seed Viability and Germination Capacity of Dalbergia melanoxylon. Botany Research Journal, 1, 82-88

[2] Amri, E. (2010) Effect of Age of the Donor Plant, IBA Treatment and Cutting Position to the Rooting Ability of Stem Cuttings in Dalbergia melanoxylon. New Foresters, 38, 183-194. http://dx.doi.org/10.1007/s11056-009-9163-6

[3] Arumugam, A. and Gopinath, K. (2011) In-Vitro Callus Development of Different Explants used for Different Medium of Terminalia arjuna. Asian Journal of Biotechnology, 3, 564-572. http://dx.doi.org/10.3923/ajbkr.2011.564.572

[4] Bryce, J.M. (1967) The Commercial Timbers of Tanzania. Forest Division, Ministry of Agriculture and Co-operatives, Moshi.

[5] Gamborg, O.L. (2002) Plant Tissue Culture. Biotechnology. Milestones. In Vitro Cellular and Developmental Biology Plant, 38, 84-92. http://dx.doi.org/10.1079/IVP2001281

[6] IUCN (2008) Red List of Threatened Plants. The IUCN Species Survival Commission, Royal Botanical Garden, Edinburgh.

[7] Kumar, C., Singh, A.K. and Nehar, S. (2010) In-Vitro Propagation and Callus Formation from Seedling of Terminalia arjuna Roxb. An International Quarterly Journal of Life Sciences, 2, 423-429.

[8] Mbuya, L.P. (1994) Useful Trees and Shrubs for Tanzania. Swedish International Development Authority, Regional Soil Conservation Unit, Morogoro.

[9] Msanga, H.P. (1999) Different Types of Trees for Plantations in Different Regions of Tanzania. MNRT Morogoro Tanzania.

[10] Murashige, T. and Skoog, F. (1962) A Revised Medium for Rapid Growth and Bio-Assays with Tobacco Tissue Culture. Physiologia Plantarum, 15, 473-497.

[11] Nshubemuki, L. (1993) Dalbergia melanoxylon: Valuable Wood from a Neglected Tree. NFT Highlights 1993-1995. Nitrogen Fixing Tree Association, Hawaii.

[12] Redhead, J.F. and Temu, A.B. (1981) Valued Timber But Neglected Tree: Mpingo (Dalbergia melanoxylon) Tanzania Association of Forester, Newsletters, 2, 8-9.

[13] Sharman, H. (1995) Investigation in the Sustainable Management of Tropical Timber Species Using Dalbergia melanoxylon as a Case Study. Unpublished MSc Thesis, University of Edinburgh, 68-69.

[14] Trigiano, R.N. and Gray, D.J. (2010) Plant Tissue Culture, Development and Biotechnology. CRC Press, Boca Raton, 186.

[15] TTSA (1995) Handling of Seeds of Dalbergia melanoxylon (African Blackwood) Seed Issue Note No. 9.

[16] Washa, B.W. (2008) Dependence of Dalbergia melanoxylon Natural Population on Root Suckers Regeneration. Journal of African Affairs, Hankuk University of Foreign studies, 24, 177-198.

[17] Washa, B.W and Nyomora, A.M.S. (2012) The Effect of Moisture and Seed Treatment on the In-Situ and Ex-Situ Re- 
generation of Dabergia melanoxylon (African Blackwood) in Pugu Forest Reserve. HURIA Journal, 10, 56-70.

[18] Washa, B.W., Nyomora, A.M.S. and Lyaruu H.V. (2012) Improving Propagation Success of D. melanoxylon (African Blackwood) in Tanzania. II: Rooting Ability of Root and Stem Cuttings of Dalbergia melanoxylon (African Blackwood) in Tanzania. Tanzania Journal of Science, 38, 43-53.

[19] Washa (2014) Seedling Production Techniques in D. melanoxylon. International Journal of Plant and Forestry Sciences, 1, $1-9$

[20] Washa (2014) Effective Cutting Type in the Rooting of Dalbergia melanoxylon in Tanzania. International Journal of AgriScience, 4, 256-259. 
Scientific Research Publishing (SCIRP) is one of the largest Open Access journal publishers. It is currently publishing more than 200 open access, online, peer-reviewed journals covering a wide range of academic disciplines. SCIRP serves the worldwide academic communities and contributes to the progress and application of science with its publication.

Other selected journals from SCIRP are listed as below. Submit your manuscript to us via either submit@scirp.org or Online Submission Portal.
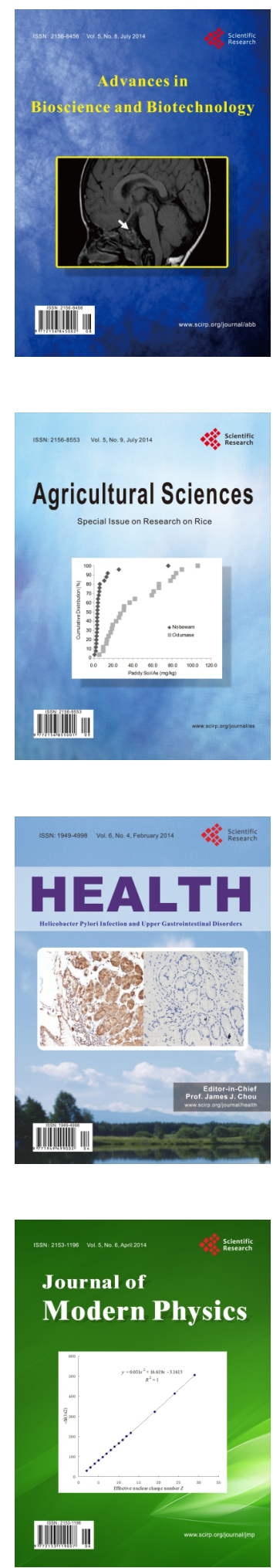
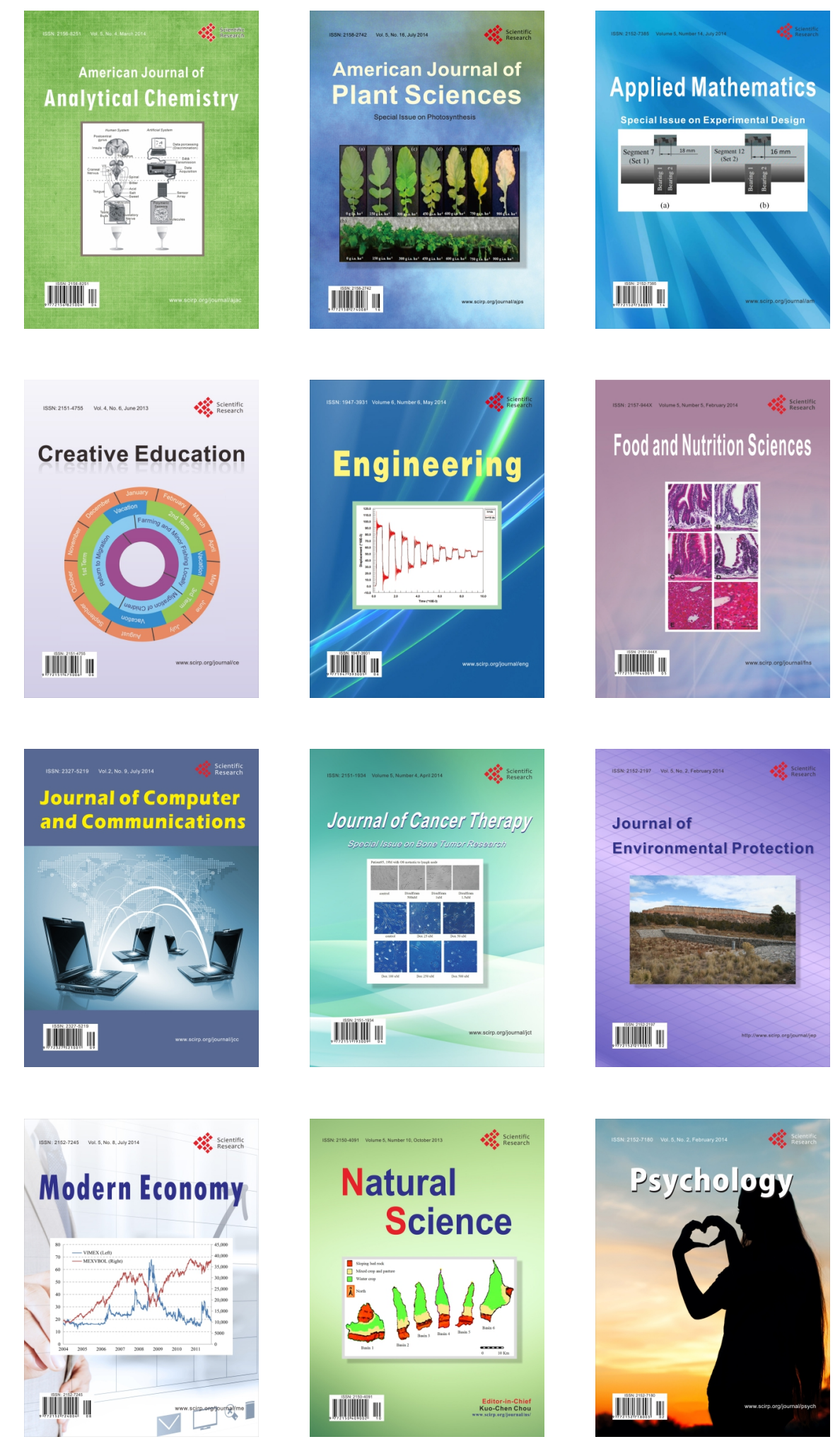